\title{
THE ASSOCIATION OF BODY MASS INDEX, BLOOD PRESSURE AND FASTING BLOOD SUGAR WITH GENDER IN THE UNITED NATIONS STAFF OF LIBERIA
}

\author{
Muhammad Imran Ibrahim, Khalida Nasreen, Shaheen Kamal
}

United Nations Mission in Liberia, Liberia

ABSTRACT

Objective: To determine the association of body mass index, blood pressure and fasting blood sugar with gender in the UN staff of Liberia.

Study Design: Cross sectional study.

Place and Duration of Study: Level-II Hospital Monrovia, Liberia, from May to Aug 2017.

Methodology: This study was conducted in the United Nation Staff of Liberia, at level-II Hospital, where, routine medical check was conducted and anthropometric measurements as well as blood pressure and fasting blood sugar values were noted. Body mass index, fasting blood sugar and blood pressure values were recorded and fasting blood sugar and blood pressure values were compared for its relationship with varying body mass index values.

Result: Total 300 individuals were monitored, out of them 226 (75.3\%) were males and 74 (24.7\%) were females. Mean weight of males was found to be $81 \pm 14.6 \mathrm{~kg}$ and for females $72.5 \pm 11.6 \mathrm{~kg}$ this difference was statistically significant $(p<0.001)$ in both males and females but there was no significant difference of gender with fasting blood glucose $(p=0.395)$, systolic blood pressure $(p=0.281)$ and diastolic blood pressure $(p=0.425)$.

Conclusion: Significant association was seen between body mass index and blood pressure in both males and females as well as for fasting blood sugar in males. Hence, simple measurement of body mass index can be used as important healths prognostic marker and thus can be used in regular routine medical assessment for maintaining and following healthy living.

Keywords: Body mass index, Diastolic blood pressure, Fasting blood sugar, Hypertension, Obesity, Systolic blood pressure.

How to Cite This Article: Ibrahim MI, Nasreen K, Kamal S. The Association of Body Mass Index, Blood Pressure and Fasting Blood Sugar with Gender in The United Nations Staff of Liberia. Pak Armed Forces Med J 2021; 71(5): 1797-1800. ～doi: https://doi.org/10.51253/pafmj.v71i5.7595

\footnotetext{
This is an Open Access article distributed under the terms of the Creative Commons Attribution License (https://creativecommons.org/licenses/by-nc/4.0/), which permits unrestricted use, distribution, and reproduction in any medium, provided the original work is properly cited.
}

\section{INTRODUCTION}

Obesity is a disease of pandemic significance especially affecting developed countries and is increasingly seen in developing countries as well, where life style is getting sedentary and eating habits have changed. Obesity brings along systemic illnesses like diabetes and hypertension, which alone can result in multisystemic complications and together can exponentially deteriorate multiple organs. Therefore, controlling obesity can be considered as first and foremost step towards normalizing one's health and doing so one can avoid all such chronic illnesses. Body mass index (BMI) is an important parameter to determine and categorize obesity and thus by simple, routine and regular monitoring of BMI, one can avoid landing up in complex and complicated health problems like diabetes and hypertension, which still, at present times, do not hold definite treatment.

This study revalidates and highlights the importance of this simple and cost-effective parameter,

Correspondence: Dr Muhammad Imran Ibrahim, Department of Radiology, Combine Militry Hospital Mangla-Pakistan

Received: 07 Dec 2020; revision received: 11 Feb 2021; accepted: 15 Mar 2021
BMI, which is also an important prognostic marker in preventing diseases like diabetes and hypertension.

\section{METHODOLOGY}

This cross-sectional study was carried at level-II hospital of United Nations' Medical Mission in Liberia from May to August 2017; formal permission was sought from the hospital ethical committee.

Inclusion Criteria was all serving UN staff of Monrovia, undergoing annual medical check-up was recorded for their height, weight, age, blood pressure and fasting blood sugar level.

Exclusion Criteria was non-consenting UN staff.

All 300 UN employees of various ethnic origin, due for routine annual medical check-up, were recorded, during study duration. Non-probability consecutive sampling technique was used, including all the staff reporting for the medical. Data was appropriately classified in groups according to BMI, blood pressure and fasting blood sugar values.

BMI classification was adopted by the Steering Committee of the Regional Office for the Western Pacific Region of WHO, the International Association for 
the Study of Obesity and the International Obesity Task Force of year 2000 (Table-I).

Data was analyzed using Statistical Package for the Social Sciences (SPSS) version 22. Mean \pm SD was calculated for quantitative variables and frequency and percentages were calculated for qualitative variable. The chi square and t-test were used. The $p$-value $\leq 0.05$ was considered statistically significant.

\section{RESULTS}

Total 300 individuals were monitored, out of them $226(75.3 \%)$ were males and $74(24.7 \%)$ were females. Amongst males 3 (1.3\%) were under weight, $61(26.9 \%)$ were in healthy BMI range; $94(41.6 \%)$ were over-weight; 62 (27.5) obese and $6(2.7 \%)$ were having morbid obesity. In females, 33 (44.7\%) were healthy; 24 $(32.4 \%)$ were over-weight and $17(22.9 \%)$ were obese, the difference of BMI was found statistically significant $(p=0.006)$ in both male and female population shown in Table-II.

Table-I: Body mass index classification by the steering committee of the regional office.

\begin{tabular}{l|c}
\hline Body Mass Index $\left(\mathbf{k g} / \mathbf{m}^{2}\right)$ & Classification \\
\hline$<18.5$ & Underweight \\
\hline $18.5-22.9$ & Healthy \\
\hline $23-24.9$ & Overweight at risk \\
\hline $25-29.9$ & Obese \\
\hline$>30$ & Morbid obesity \\
\hline
\end{tabular}

Table-II: Association of gender and body mass index.

\begin{tabular}{|c|c|c|c|}
\hline Parameters & $\begin{array}{c}\text { Male }(n=226) \\
n(\%)\end{array}$ & $\begin{array}{c}\text { Female } \\
(n=74) n(\%)\end{array}$ & $\begin{array}{c}p- \\
\text { value }\end{array}$ \\
\hline \multicolumn{4}{|c|}{ Body Mass Index $\left(\mathrm{kg} / \mathrm{m}^{2}\right)$} \\
\hline Underweight & $3(1.3)$ & $33(44.7)$ & \multirow{5}{*}{0.006} \\
\hline Healthy & $61(26.9)$ & & \\
\hline Overweight at risk & $94(41.6)$ & 24 (32.4) & \\
\hline Obese & $62(27.5)$ & $17(22.9)$ & \\
\hline Morbid obesity & $6(2.7)$ & & \\
\hline
\end{tabular}

Mean weight of males was found to be $81 \pm 14.6$ $\mathrm{kg}$ and for females $72.5 \pm 11.6 \mathrm{~kg}$ statistically significant $(p<0.001)$ difference was seen in both males and females, Mean BSF values for males was $5.3 \pm 3.2 \mathrm{mmol}$ $/ \mathrm{L}$ and for females $5.0 \pm 0.7 \mathrm{mmol} / \mathrm{L}$, mean systolic BP for males was $125.8 \pm 16.3 \mathrm{mmHg}$ and $123.5 \pm 15.2$ $\mathrm{mmHg}$ for females. Means diastolic BP of males was $83 \pm 9.7 \mathrm{mmHg}$ and $82 \pm 8.2 \mathrm{mmHg}$ for females. There was no significant difference of fasting blood glucose $(p=0.395)$, systolic BP $(p=0.281)$ and diastolic BP $p=$ 0.425 shown in Table-III.

\section{DISCUSSION}

Obesity, worldwide has doubled since 1980 and $65 \%$ of the world's population live in countries where
Table-III: Association of gender with weight, fasting blood glucose and blood pressure.

\begin{tabular}{l|c|c|c}
\hline \multirow{2}{*}{ Parameters } & Male (n=226) & Female (n=74) & $\begin{array}{c}p \text { - } \\
\text { value }\end{array}$ \\
\cline { 2 - 3 } & \multicolumn{2}{|c|}{ Mean \pm SD } & $<0.001$ \\
\hline Weight $(\mathrm{Kg})$ & $81.0 \pm 14.6$ & $72.5 \pm 11.6$ & 0.395 \\
\hline $\begin{array}{l}\text { Fasting blood } \\
\text { glucose (mmol/L) }\end{array}$ & $5.3 \pm 3.2$ & $5.0 \pm 0.7$ & 0.281 \\
\hline $\begin{array}{l}\text { Systolic Blood } \\
\text { Pressure (mmHg) }\end{array}$ & $125.8 \pm 16.3$ & $123.5 \pm 15.2$ & 0.425 \\
\hline $\begin{array}{l}\text { Diastolic Blood } \\
\text { Pressure(mmHg) }\end{array}$ & $83 \pm 9.7$ & $82 \pm 8.2$ & 0.25 \\
\hline
\end{tabular}

being overweight and obese kill more people than being underweight. ${ }^{1}$ Commonest cause of obesity is eating more calories and sedentary life style, sitting in front of desk or television screens. This, modern life style results in increased weight gain and peculiar body fat distribution, affecting abdominal region more. These combined effects result in inadequate insulin production as well as raised blood pressure by way of raised mean blood pressure as well as stroke volume. The most recent guidelines from American College of Endocrinology recommend weight reduction along with optimized life-style modification for the control of prediabetes and type 2 diabetes. ${ }^{2}$ Close relationship has been shown by multiple studies, between obesity and raised blood pressure which consequently results in multiple complications. ${ }^{3-6}$

BMI is one of the simplest and most commonly used parameters for measuring obesity and is calculated as weight in kilogram divided by square of the height in meters. Diseases like hypertension and diabetes have been argued to be related with obesity. By routine monitoring of simple BMI value, one can easily prognosticate health risk of these diseases.

In one of the longest running prospective studies, conducted in Framingham, the Framingham heart study (FHS), which started in 1944, showed that obesity is the cause of hypertension in at least $28 \%$ of those male participants and $26 \%$ of those female participants. Similarly, another long prospective study conducted in female nurses of Harvard Medical School, Boston for 16 years-showed obesity being the risk factor for the new onset hypertension in at least $44 \%$ of those participants. Thus, medical literature over the years has already placed immense stress on the maintenance of ideal weight and BMI for leading a healthy life.

Our study has shown a positive direct progressive relation in terms of increasing BMI values with hypertension. Many previous studies, with larger sample size (more than 700,000 cohorts), have also shown 
BMI, Blood Pressure and Fasting Blood Sugar

similar results of linear correlation between BMI and blood pressure. ${ }^{7}$

Analysis of obesity prevalence amongst adolescent has shown varying results. Adolescent obesity screening data from North America suggested rising obesity between 1999 and 2011 but remained static between 2009 and 2011.8 Public schools of New York, showed decrease in obesity prevalence between 2006-2007 and 2010-2011. ${ }^{9}$ Other researchers have shown increase in obesity prevalence among US schools between 20012002 and 2005-2006. ${ }^{10}$ According to a survey in 2015, Pakistan has been ranked 9th out of 188 countries for the countries with most obesity. ${ }^{11}$

Obesity is considered mother of many illnesses and carries greater risk factors with increasing age for diseases like cardiac problems, type 2 diabetes, stroke, numerous cancers and osteoarthritis. ${ }^{12}$ Mechanism of raised blood pressure with raised BMI is not completely understood but number of possible explanations include; autonomic dysfunction; insulin-resistance; abnormalities in vascular structure and function. They all are presumed to be underlying mechanism of raised blood pressure due to raised BMI values. ${ }^{13}$ Similar obesity related hormonal and vascular dysfunctionality is argued to be responsible for polycystic disease in females. ${ }^{14}$

Raised BMI has been postulated to be directly related to raise fasting blood sugar and ultimately results in appearance of early onset of non-insulin dependent diabetes. One of the Swedish long prospective studies which was conducted on normoglycemic individuals and was followed up till appearance of diabetes showed that those with raised BMI are more prone to get diabetes in future. Robust weight control program with combined very low-calorie diet has been postulated to cause remission from diabetes. ${ }^{15}$ All these regimes revolve around strict glycemic control which infact decreases the onset and progression of microvascular and neuropathic complications. ${ }^{16-17}$

Statistically significant correlation exists between BMI and blood pressure as is seen in our study; which is in agreement with several such studies performed previously in countries like Crete, South Africa, India and Nigeria. ${ }^{18}$ Our study showed significant correlation between BMI and FBS only in male subjects but not in females; which agrees to previous studies like that of Zaria in Nigeria. ${ }^{19}$ Nevertheless, few other studies have showed similar correlation of BMI and FBS in both gender. ${ }^{20}$

\section{CONCLUSION}

There was a significant correlation between BMI and blood pressure in UN staff of Liberia which can be equally applied in both males and females. However, correlation of fasting blood sugar to BMI was only established in male staff of UN, not in females. Possible explanation can be racial and ethnic differences, which result in different body fat distribution. BMI still holds as an important health parameter and can prognosticate chronic illness like hypertension and to some extent diabetes.

\section{LIMITATION OF STUDY}

There were number of limitations in our study. Since it was conducted in, a multinational setup therefore lacked ethnic and regional uniformity but at the same time, it was a rare opportunity to revalidate previous studies at multinational level. Secondly, sample size was small reason being that due to multi-national and multi-ethnicity, prevalence of disease entity for a single region/ethnic group could not be applied in this case. However, larger sampling size with continuation of such study can revalidate our data.

\section{Conflict of Interest: None.}

\section{Authors' Contribution}

MII: Data collection, data analysis, Interpretation of data, $\mathrm{KN}$ : Data analysis, reveiw, SK: data analysis, proof reading.

\section{REFERENCES}

1. Jones R, Jewell J, Saksena R, Ramos Salas X, Breda J. Overweight and obesity in children under 5 years: surveillance opportunities and challenges for the WHO European region. Front Public Health 2017; 5(2): 58-62.

2. Garber AJ, Abrahamson MJ, Barzilay JI, Blonde L, Bloomgarden ZT, Bush MA, et al. Consensus statement by the american association of clinical endocrinologists and american college of endocrinology on the comprehensive type 2 diabetes management algorithm-2017 executive summary. Endocr Pract 2019; 25(1): 69100.

3. Wen X, Gillman MW, Rifas-Shiman SL, Sherry B, Kleinman K, Taveras EM. Decreasing prevalence of obesity among young children in Massachusetts from 2004 to 2008. Pediatr 2012; 129(5): 823-831.

4. Drake KM, Beach ML, Longacre MR, Mackenzie T, Titus LJ, Rundle AG, et al. Influence of sports, physical education, and active commuting to school on adolescent weight status. Pediat 2012; 130(2): e296-e304.

5. Rossen LM, Schoendorf KC. Measuring health disparities: Trends in racial-ethnic and socioeconomic disparities in obesity among 2- to 18-year old youth in the United States, 2001-2010. Ann Epidemiol 2012; 22(10): 698-704.

6. Kant AK, Graubard BI. Family income and education were related with 30-year time trends in dietary and meal behaviors of American children and adolescents. J Nutr 2013; 143(5): 690-700.

7. Chorin E, Hassidim A, Hartal M, Havakuk O, Flint N, Ziv-Baran $\mathrm{T}$, et al. Trends in adolescents obesity and the association between BMI and blood pressure: a cross-sectional study in 714,922 healthy teenagers. Am J Hypert 2015; 28(9): 1157-1163.

8. Kann L, Mcmanus T, Harris WA, Shanklin SL, Flint KH, Hawkins J, et al. youth risk behavior surveillanceu nited states, 2015. MMWR Surveill Summ 2016; 65(6): 1-174. 


\section{BMI, Blood Pressure and Fasting Blood Sugar}

9. Morbidity and Mortality Weekly Report (MMWR). Centers for Disease Control and Prevention. Centers for Disease Control and Prevention; 2017 [Internet] Available from: https://www.cdc. gov/mmwr/index.html [Accessed on December 26, 2017].

10. Iannotti RJ, Wang J. Trends in physical activity, sedentary behavior, diet, and BMI among US adolescents, 2001-2009. Pediat 2013; 132(4): 606-614.

11. Pakistan 9th most obese country: Study-The Express Tribune. The Express Tribune. 2017, [Internet] Available from: https:// tribune.com.pk/story/714845/ pakistan-9th-most-obese-countrystudy/ [Accessed on December 26, 2017]

12. Ogden CL, Carroll MD, Kit BK, Flegal KM. Prevalence of childhood and adult obesity in the United States, 2011-2012. J Am Med Assoc 2014; 311(8): 806-810.

13. Klawitter J, Reed-Gitomer BY, Mcfann K, Pennington A, Klawitter J, Abebe KZ, et al. Endothelial dysfunction and oxidative stress in polycystic kidney disease. Am J Physiol Renal Physiol 2014; 307(11): F1198-206.

14. Skaug EA, Madssen E, Aspenes ST, Wisløff U, Ellingsen O. Cardiovascular risk factors have larger impact on endothelial function in self-reported healthy women than men in the HUNT3 Fitness study. PLoS One 2014; 9(7): e101371.
15. Steven S, Hollingsworth KG, Al-Mrabeh A, Avery L, Aribisala B, Caslake M, et al. Very low-calorie diet and 6 months of weight stability in type 2 diabetes: pathophysiological changes in responders and nonresponders. Diabetes Care 2016; 39(5): 808-815.

16. Inzucchi S, Bergenstal R, Buse J, Diamant M, Ferrannini E, Nauck M, et al. Management of hyperglycaemia in type 2 diabetes, 2015: a patient-centred approach. Update to a Position Statement of the American Diabetes Association and the European Association for the Study of Diabetes. Diabetol 2015; 58(3): 429-442.

17. American Diabetes Association. (6) Glycemic targets. Diabetes Care 2015; 38(Suppl): S33-40.

18. Bhattacharya D Banerjee D. Correlation of obesity indices with blood pressure and blood glucose level among young medical students. IOSR J Dent Med Sci 2017; 16(02): 59-63.

19. Bakari AG, Onygemelukwe GC, Sani BG, Aliyu IS, Hassan SS, Aliyu TM. Relationship between random blood sugar and body mass index in an African population. Int J Diabetes Metab 2006; 14(1): 144-145.

20. Abiodun OA, Jagun OA, Olu-Abiodun O, Sotunsa, JO. Correlation between Body mass index, Waist Hip ratio, blood sugar levels and blood pressure in apparently healthy adult Nigerians. IOSR J Dent Med Sci 2014; 13(11): 56-61. 